\title{
Sistem Informasi Pengukuran Efektivitas Produksi Berbasis Web (Studi Kasus : PT. Beiersdorf Indonesia)
}

\author{
Diovianto Putra Rakhmadani ${ }^{1 *}$, Soetam Rizky Wicaksono ${ }^{2}$ \\ $1 *, 2)$ Fakultas Sains dan Teknologi, Program Studi Sistem Informasi, \\ Universitas Ma Chung \\ Jl. Villa Puncak Tidar N-01, Malang 65651 \\ email : myzheeper@yahoo.com, soetam.rizky@machung.ac.id
}

\begin{abstract}
The effectiveness of the production is a must knowledge in a manufacture company, because it is closely linked to the success level of a company, if effectiveness reaching high level, it will lead to be successful in terms of meeting production targets. It is also happened at PT Beiersdorf Indonesia which requires method to measure the effectiveness of production in their companies, particularly in Elastoplast production division. PT Beiersdorf Indonesia requires certain method IPC computerized checklist which the system can give information related to the evaluation of the effectiveness of production. Based upon these problems, it is clearly stated that they need to use innovation in Effectiveness Level Measurement Information System Production. This information system is designed to help the all involved employees the process, documenting, and directly controls the activity of production. in this study, by creating the new system will help the company to conduct an evaluation of the production process.
\end{abstract}

Keywords: information system, production effectivity measurement, effectiveness

\begin{abstract}
Abstrak
Tingkat efektivitas produksi merupakan suatu hal yang patut diketahui oleh suatu perusahaan, dikarenakan hal ini berhubungan erat dengan tingkat keberhasilan suatu perusahaan, apabila tingkat efektivitas perusahaan tersebut tinggi, maka suatu perusahaan dapat dikatakan sukses dalam hal memenuhi target produksi. Hal ini juga yang melatarbelakangi PT Beiersdorf Indonesia memerlukan suatu metode untuk mengukur tingkat efektivitas produksi di perusahaan mereka, khususnya di divisi produksi Hansaplast. PT Beiersdorf Indonesia membutuhkan metode pengisian IPC Checklist yang terkomputerisasi dimana sistem tersebut dapat memberi informasi yang berhubungan dengan evaluasi terhadap tingkat efektivitas produksi. Berdasarkan permasalahan tersebut, maka diberikan sebuah solusi dengan menggunakan inovasi Sistem Informasi Pengukuran Tingkat Efektivitas Produksi. Sistem Informasi ini dibuat untuk membantu para pelaku yang terlibat dalam mengolah, mendokumentasikan, dan mengontrol secara langsung aktivitas produksi. maka dalam penelitian ini, dengan menciptakan sistem baru akan membantu perusahaan dalam melakukan kegiatan evaluasi terhadap proses produksi yang berlangsung.
\end{abstract}

Kata Kunci: sistem informasi, pengukuran efektivitas produksi, efektivitas

\section{Pendahuluan}

Pengukuran tingkat efektifitas produksi dapat digunakan sebagai tolok ukur tingkat keberhasi-

* Korespondensi Penulis lan suatu perusahaan. Apabila tingkat efektivitas perusahaan tersebut tinggi, maka suatu perusahaan dapat dikatakan mampu memenuhi target produksi . Target produksi merupakan hasil bagi antara jumlah order dengan waktu / hari produksi, sehingga akan didapat jumlah 
target produksi dalam satu kurun waktu tertentu (Caruana \& Einav, 2006). Selain itu, dari pengukuran tersebut akan dapat dijadikan sebagai suatu evaluasi terhadap seluruh komponen produksi yang terjadi selama proses produksi, baik dari bagian mesin, sumber daya manusia, hingga bahan baku yang terlibat didalamnya.

Pengukuran efektivitas produksi juga dilakukan di PT Beiersdorf Indonesia. PT Beiersdorf Indonesia merupakan sebuah perusahaan multinasional dari Jerman yang bergerak di bidang consumer good, dengan produk utamanya Nivea dan Hansaplast. Pengukuran dilakukan agar perusahaan dapat memenuhi target produksi yang telah dibuat sehingga tetap menjaga nama perusahaan agar tetap berada di level tertinggi yang sesuai dengan visi dan misi yang dimiliki oleh perusahaan. Selain itu, pengukuran efektivitas produksi di perusahaan juga dapat dijadikan sebagai review terhadap kinerja produksi pada suatu waktu, sehingga dapat dijadikan sebagai informasi terhadap rencana kegiatan produksi kedepannya.

Dalam melakukan proses produksi, PT Beiersdorf Indonesia menggunakan mesin belt conveyor dan metode IPC Checklist dalam melakukan Quality Control. IPC Checklist dalam ruang lingkup ini merupakan sebuah metode pengambilan sampel produk pada kurun waktu tertentu untuk memantau kualitas produksi yang terjadi di setiap pengerjaan produksi (Davidek, 2015).

Dalam kegiatan berproduksi, Quality Control mutlak diperlukan guna mencapai suatu efektivitas produksi (Homayounizadpanah \& Baqerkord, 2012). Oleh karena itu, agar dapat meningkatkan efektivitas produksi, maka dibutuhkan sebuah pengukuran efektivitas produksi yang berdasar pada Quality Control.

\section{Kajian Pustaka}

Efektivitas adalah pencapaian target output yang diukur dengan cara membandingkan output anggaran atau seharusnya (OA) dengan output realisasi atau sesungguhnya (OS), jika $(\mathrm{OA})>$ (OS) disebut efektif (Schermerhorn Jr., 2009). Definisi lain dari efektivitas adalah seberapa besar tingkat kelekatan output yang dicapai dengan output yang diharapkan dari sejumlah input (Budi, 1984). Sehingga dapat dapat disimpulkan bahwa efektivitas adalah suatu ukuran yang menyatakan seberapa jauh target (kuantitas,kualitas dan waktu) yang telah dicapai oleh manajemen, yang mana target tersebut sudah ditentukan terlebih dahulu.
IPC (In-Process Control) Checklist merupakan suatu metode Quality Control yang bertujuan untuk melakukan kendali terhadap produksi suatu produk agar tetap memenuhi standar yang telah ditetapkan oleh perusahaan. IPC Checklist menggunakan metode pengecekan output produksi dengan cara pengambilan beberapa sampel secara acak dan dihitung sampel error yang didapati selama proses berlangsung (ECA Academy, 2015).

\subsection{Desain Sistem}

Didalam pengisian IPC Checklist yang digunakan di PT Beiersdorf Indonesia terdapat beberapa data yang menunjang di dalam sistem pengukuran tingkat efektivitas produksi ini antara lain :

\section{Nomor batch}

2. Jumlah produk(sample)

3. Jumlah produk cacat

4. Jumlah produk sesuai standar

Nomor batch merupakan sebuah penomoran oleh pihak produksi terhadap masing-masing lini pengerjaan produk sesuai dengan bahan baku yang dimiliki dan rencana produksi mereka, nomor batch diisikan pada setiap pengerjaan produksi, dimana setiap pengerjaan produksi mempunyai penomoran batch yang berbeda-beda. Dari suatu pengerjaan batch, akan diambil beberapa sampel produk secara acak, dan dihitung jumlah produk cacat dan produk sesuai dengan beberapa parameter yang telah ditentukan, yang kemudian akan dibandingkan antara target produksi dengan output produksi sebenarnya. Hasil dari perbandingan tersebut akan menentukan apakah hasil dari pengerjaan produksi suatu shift telah memenuhi target produksi dan memenuhi standar efektivitas produksi atau belum.

Berdasarkan hasil dari wawancara terhadap Manajer Produksi di PT Beiersdorf Indonesia , dapat diambil kesimpulan bahwa pengerjaan IPC Checklist di area produksi Hansaplast (PT Beiersdorf Indonesia) masih dilakukan secara manual selama ini. Adapun beberapa pihak yang terlibat dalam sistem ini antara lain:

\section{QM (Quality Management)}

Merupakan bagian yang melakukan kontrol penuh terhadap kualitas suatu produk dan mengatur penuh terhadap Quality Control tiap produksi di PT Beiersdorf Indonesia.

2. Karyawan Merupakan pekerja yang mengisikan secara 
langsung form pengisian IPC Checklist di lapangan.

3. Supervisor

Merupakan bagian yang mengawasi setiap proses produksi yang berlangsung di area produksi Nivea maupun Hansaplast.

4. Manajer Produksi

Merupakan level manajer yang bertugas mengawasi dan melakukan kontrol penuh terhadap proses berlangsungya produksi di PT Beiersdorf Indonesia.

Berikutnya dilakukan perancangan alur sistem new yang didalamnya melibatkan sistem informasi pengukuran yang dibuat. Hasil dari perancangan sistem baru dapat dilihat pada diagram kerja di Gambar 1.

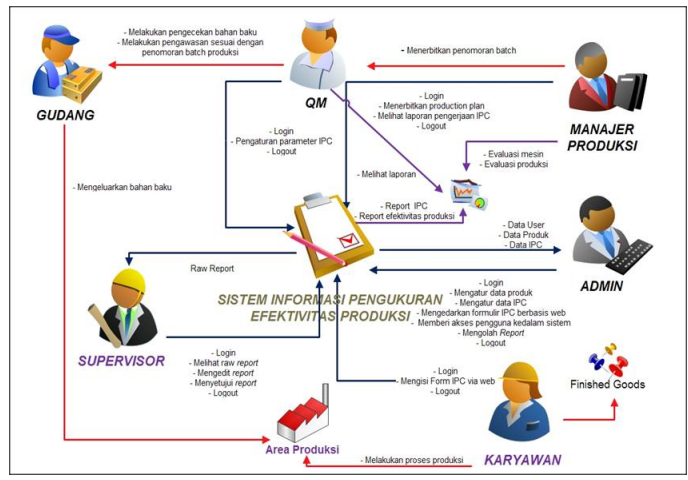

Gambar 1: Workflow Sistem Baru

Pada saat awal, Manajer Produksi melakukan rencana produksi sesuai dengan pengelompokan dari penomoran batch yang dibuat. Selanjutnya Manajer Produksi login ke dalam sistem dan menerbitkan production plan sesuai dengan pengelompokan batch.

Langkah berikutnya adalah dari pihak QM (Quality Management) melakukan pengawasan bahan baku dari gudang, dan melakukan pengawasan terhadap pengelompokan bahan baku sesuai dengan perintah produksi dari Manajer Produksi. Kemudian pihak Gudang mengeluarkan bahan baku yang telah dikelompokkan ke dalam area produksi Hansaplast.

Pihak QM dapat melakukan login ke dalam sistem dan mengatur paramater IPC produk yang akan digunakan untuk pengisian IPC oleh Karyawan. Sedangkan Supervisor login ke dalam sistem untuk melihat production plan yang telah diterbitkan oleh Manajer Produksi ,serta memproses bahan baku yang telah dikeluarkan dari gudang.

Dari sisi Karyawan dapat masuk ke dalam sistem dan hanya melihat production plan serta melakukan proses produksi. Kemudian pihak Karyawan login ke dalam sistem dan melakukan pengisian form IPC melalui sebuah gadget.

Selain menghasilkan produk jadi, Karyawan juga akan menghasilkan laporan pengerjaan IPC sebagai syarat wajib produksi di perusahaan. Dari hasil laporan pengerjaan tersebut pihak $\mathrm{Su}$ pervisor juga dapat memantau pengerjaan IPC yang dilakukan oleh Karyawan, dengan cara masuk ke dalam sistem.

Apabila pengisian lancar atau tidak ada kendala, Supervisor dapat melakukan persetujuan pengerjaan IPC yang telah selesai dikerjakan via web. Hasil dari laporan persetujuan IPC oleh Supervisor akan menjadi sebuah end report yang dapat diakses oleh Manajer Produksi maupun QM.

Manajer Produksi login ke dalam sistem, dan melihat hasil dari pengerjaan IPC. Kemudian Manajer Produksi dapat menjadikan laporan sebagai bahan evaluasi mesin produksi, evaluasi pengerjaan produk, dan laporan efektivitas produksi.

Untuk kepentingan pembuatan sistem informasi, maka hasil dari perancangan awal tersebut kemudian diterjemahkan menjadi DFD. Dalam makalah ini hanya ditampilkan level 0 yakni diagram konteks dari perancangan awal seperti terlihat pada gambar 2 .

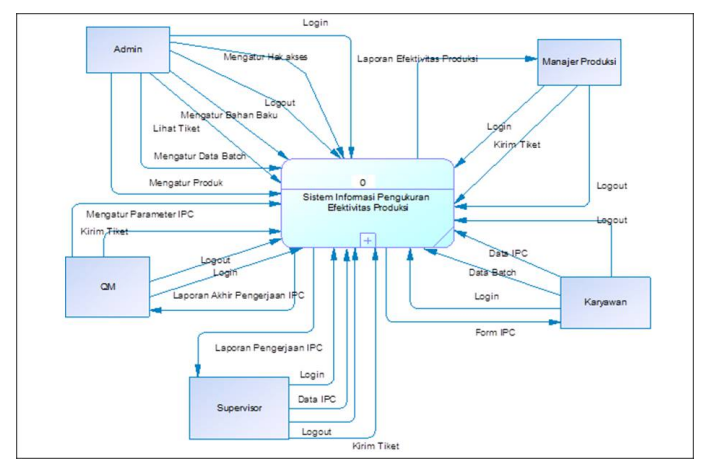

Gambar 2: Diagram Konteks

\section{Hasil dan Pembahasan}

Pengguna yang melakukan proses login dengan level administrator, akan masuk ke dalam sistem sebagai Administrator. Fungsi utama seorang administrator adalah melakukan pengaturan master data IPC, bahan baku, pengaturan mesin produksi, hak akses pengguna kedalam sistem, dan pengaturan batch.

Seorang Administrator juga bertugas untuk melakukan pengaturan data mesin produksi 
yang akan digunakan didalam sistem. Pengaturan tersebut diantaranya pengaturan master data mesin mempunyai informasi antara lain Kode mesin, Keterangan, dan Status mesin, seperti tertera pada Gambar 3.

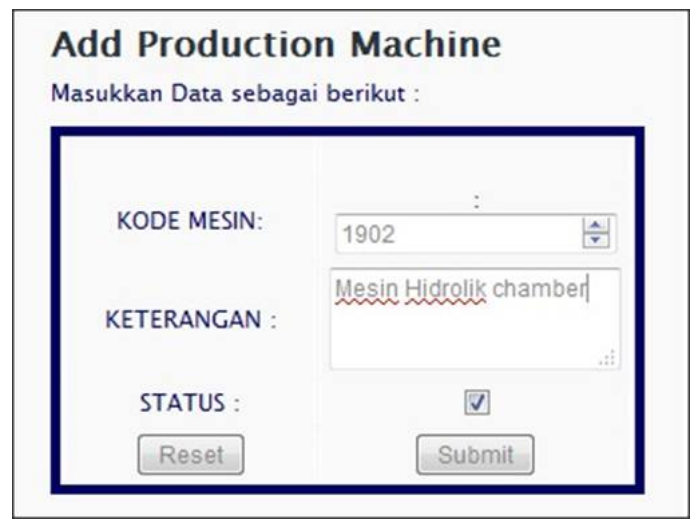

Gambar 3: Tampilan menu penambahan mesin produksi

Pengguna dengan hak akses karyawan berperan sebagai pelaku yang mengerjakan proses pengisian IPC Checklist. Setelah masuk kedalam sistem, pengguna dalam hal ini Karyawan, akan memilih bagian kerja mereka, dimana karyawan yang sedang melakukan proses produksi atau proses pengisian IPC Checklist memilih sesuai dengan penempatan area produksi mereka, baik di area produksi Hansaplast maupun Nivea.

Setelah Karyawan melakukan pemilihan bagian kerja, mereka akan diminta untuk memilih nama produk ataupun kode produk yang akan mereka kerjakan sesuai dengan perintah produksi yang telah dikeluarkan. Setelah memilih produk yang akan mereka kerjakan. Pada halaman ini, karyawan akan memilih bagian produk pengerjaan mereka, bagian yang tersedia antara lain bagian Dressing dan Packing.

Halaman pengisian batch akan muncul setelah Karyawan memilih pada bagian pengerjaan mana mereka melakukan pengisian IPC Checklist. Halaman ini akan meminta Karyawan untuk mengisikan beberapa data, antara lain :

\section{Nomor Batch}

2. Jumlah atau ukuran per batch dan satuan yang digunakan

3. Mesin Produksi yang digunakan

4. Tanggal pengerjaan IPC Checklist atau pengerjaan batch

5. Jam Mulai Pelaksanaan aktifitas produksi

6. Bahan baku yang digunakan

Contoh pengisian tampak pada Gambar 4.

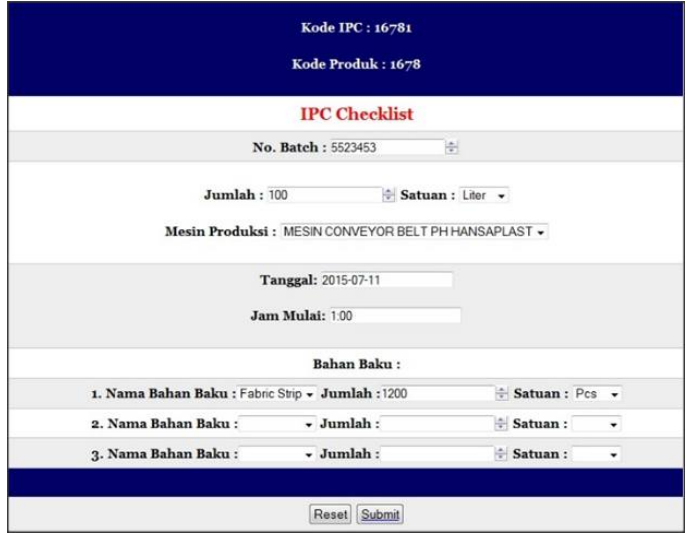

Gambar 4: Tampilan pengisian batch IPC

Selanjutnya pada halaman awal pengisian IPC , Karyawan akan diminta untuk memasukkan jam pengambilan sampel untuk pengecekan IPC dan jumlah sampel yang digunakan sebagai pengecekan. Halaman ini merupakan halaman yang diisikan oleh karyawan sesuai dengan kondisi nyata pekerjaan produksi mereka.

Berdasarkan sejumlah sampel yang diambil, akan ada berapa produk yang cacat atau tidak memenuhi standar sesuai dengan parameter yang diminta. Pengisian Parameter ini akan berlanjut hingga semua parameter yang diminta telah selesai diuji. Dalam pengujian dengan nomor batch 5523453 dimasukkan data ke dalam 4 parameter yang telah ditentukan sebelumnya. Hasil dari pengisian tampak pada halaman laporan di Gambar 5.

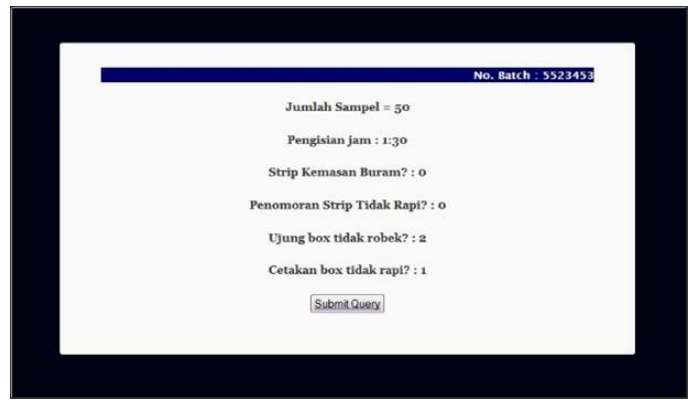

Gambar 5: Tampilan pengisian parameter IPC sukses

Setelah Karyawan melakukan pengisian IPC Checklist dan proses produksi dengan penomoran batch telah selesai dilakukan, Karyawan akan mengakses halaman akhir dari pengisian IPC Checklist. Pada halaman ini, Karyawan akan diminta untuk mengisi data :

1. Jam selesai produksi

2. Output real 
3. Catatan selama proses produksi atau proses pengerjaan IPC berlangsung. Apabila selesai, Karyawan akan menekan tombol "Submit" dan akan diarahkan ke halaman selanjutnya.

Hal pertama yang didapat dari Supervisor, setelah pengerjaan IPC oleh Karyawan adalah notifikasi. Notifikasi merupakan fitur yang digunakan untuk menandai apabila ada batch baru yang masuk atau tidak, apabila ada pengerjaan batch yang telah dikerjakan dan baru masuk, maka notifikasi akan menyala merah dan akan menunjukkan pengerjaan batch apa saja yang telah dikerjakan. Dalam ujicoba, data dengan penomoran batch 5523453 muncul sebagai notifikasi batch yang baru dikerjakan. Hasil batch tampak pada Gambar 6.

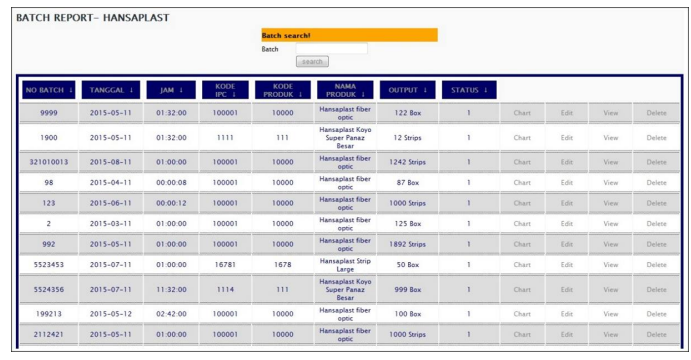

Gambar 6: Tampilan laporan batch pengerjaan

Supervisor dapat memantau kinerja pengisian IPC oleh Karyawan melalui sebuah State. State merupakan sebuah aturan yang mengatur aksi dari kegiatan produksi berdasarkan data persentase Pcs Not ok yang didapat dari membagi hasil dari jumlah sampel produk dengan jumlah Pcs Not ok. Perintah dari aturan State dijelaskan pada Tabel 1.

Tabel 1: Penjelasan aturan "State"

\begin{tabular}{|c|c|c|}
\hline Persentase & Keterangan & Aksi \\
\hline $\mathrm{i}=10 \%$ & Oke & Produksi oke \\
\hline $\mathrm{i}=30 \%$ & Warning & $\begin{array}{c}\text { Perlu adanya } \\
\text { pengecekan mesin } \\
\text { atau kinerja produksi }\end{array}$ \\
\hline$i 30 \%$ & Danger & $\begin{array}{c}\text { Hentikan aktifitas } \\
\text { produksi untuk } \\
\text { sementara }\end{array}$ \\
\hline
\end{tabular}

Pada halaman laporan gragik pengerjaan batch, ditampilkan laporan berbentuk grafik dengan penomoran batch yang telah dikerjakan oleh Karyawan, dalam ujicoba ini, yang ditampilkan adalah batch dengan penomoran 5523453. Grafik ini berisi mengenai data pengisian IPC Checklist pada jam-jam yang telah dilakukan pengisian dan persentase Pcs Not ok atau produk cacat. Selain Supervisor, menu ini juga dapat diakses oleh QM dan Manajer Produksi. Contoh grafik tampak pada gambar 7 .

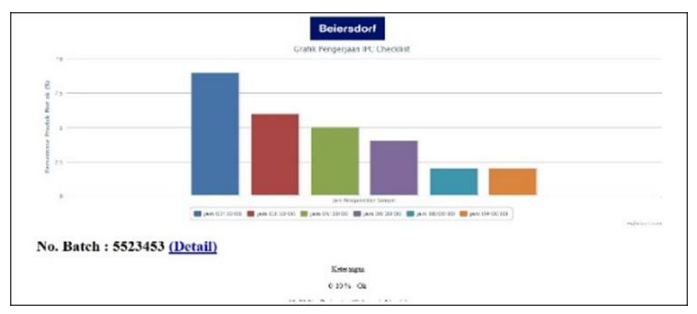

Gambar 7: Tampilan grafik pengerjaan IPC

Manajer Produksi dapat melihat laporan pengerjaan IPC Checklist sesuai dengan tanggal pengerjaannya. Informasi tersebut disajikan dalam bentuk grafik dan ditunjukkan informasi mengenai pengerjaan IPC Checklist pada suatu tanggal tertentu, dimana informasi yang disajikan adalah banyaknya pengerjaan batch yang dikerjakan pada tanggal tersebut, dan laporan efektivitas produksi yang dihasilkan. Pada uji coba ini disajikan data pengerjaan pada tanggal 11-07-2015 pada Gambar 8.

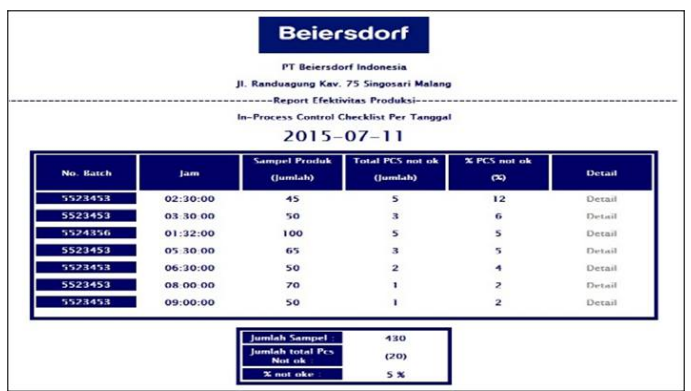

Gambar 8: Tampilan laporan detail cacat produk per tanggal

Seorang Manajer Produksi mempunyai fitur untuk mengetahui laporan akhir yang berisi mengenai detail pengerjaan IPC Checklist, oleh karena itu, diperlukan sebuah laporan yang mampu menampilkan beberapa data pengerjaan IPC Checklist secara detail. Dalam uji coba ini, menampilkan laporan efektivitas produksi secara detail pada batch dengan nomor pengerjaan 5523453. Informasi di dalam laporan ini dapat disimpan ke dalam format PDF melalui software Nitro Pro ataupun langsung dicetak seperti tampak pada Gambar 9.

\section{Kesimpulan dan Saran}

Setelah melakukan tahapan pengujian, dapat diambil beberapa kesimpulan yaitu : 


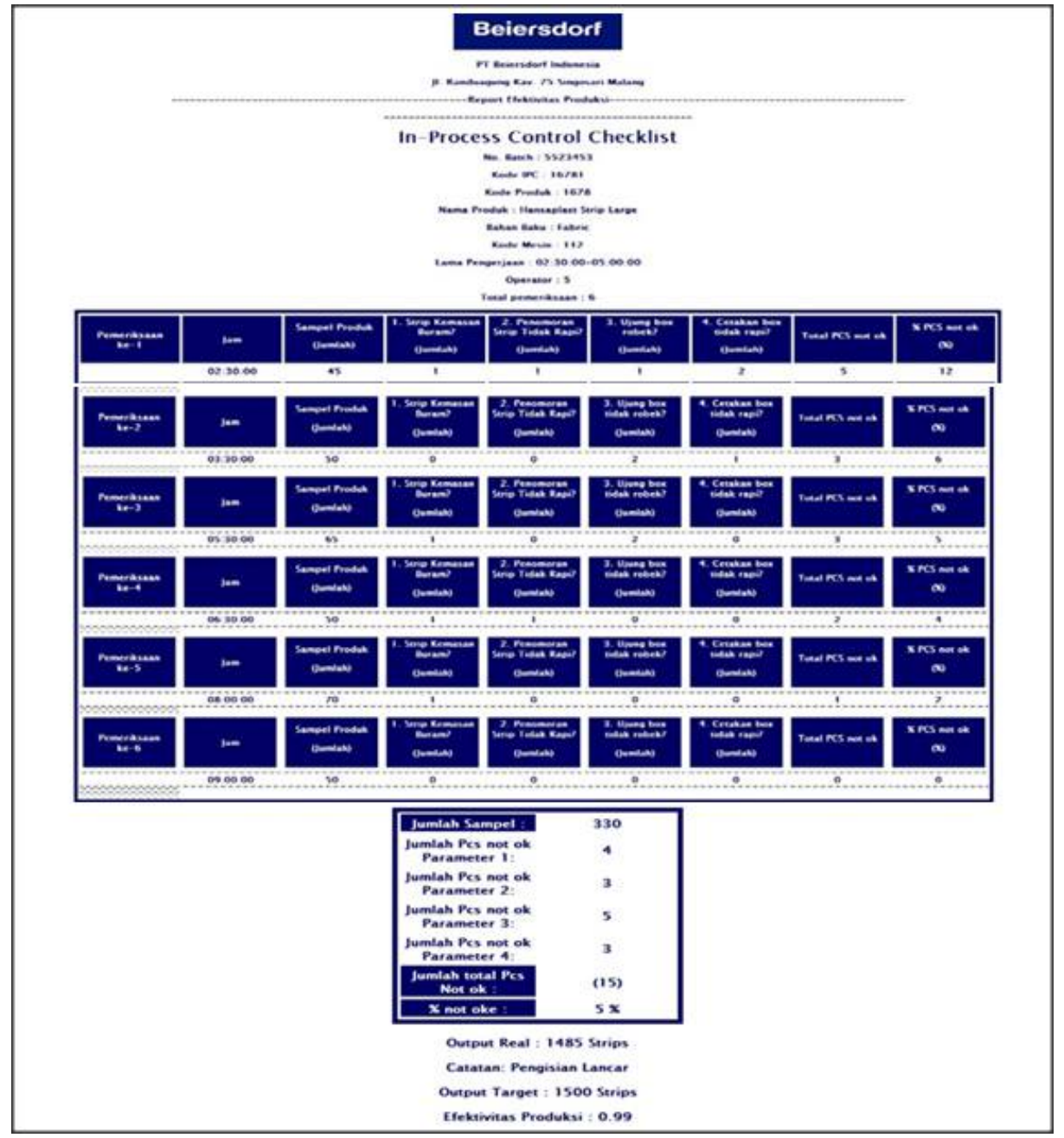

Gambar 9: Tampilan end report

1. Sistem ini membantu dalam hal penyajian data yang disajikan secara lengkap dan dalam waktu yang real

2. Informasi yang diperoleh dari pengisian IPC Checklist berbasis web ini dapat lebih cepat diterima oleh para pengambil keputusan jika dibandingkan dengan sistem lama (manual), dalam hal yang berhubungan dengan laporan kegiatan produksi

3. Informasi yang disajikan di dalam sistem ini dapat membantu dalam hal pengambilan keputusan baik itu dalam hal pengerjaan batch, laporan penggunaan mesin produksi, dan laporan efektivitas produksinya.

IPC Checklist Online adalah sebuah aplikasi yang kelak saling terintegrasi dan akan menjadi pengganti pengerjaan IPC Checklist secara manual. Oleh karena itu, diperlukan pengembangan dan penelitian lebih lanjut sebagai berikut:

1. Untuk pengembangan selanjutnya, perlu diadakan pengintegrasian sistem ke dalam
SAP yang sedang digunakan oleh perusahaan

2. Sistem harus di hosting ke dalam sebuah server dengan kapasitas yang besar, karena penggunaan sistem ini akan memakan banyak tempat apabila dikerjakan secara berlanjut dalam beberapa tahun kedepan. 


\section{Daftar Pustaka}

Budi, S. P. (1984). Dalam Menuju SDM Berdaya. Jakarta: Bumi Aksara.

Caruana, G., \& Einav, L. (2006). Production Targets. Retrieved from CEMFI: http://www.cemfi.es/ caruana/targets.pdf

Davidek, J. (2015, 07 10). In-Process Quality Control. Retrieved from Encyclopedia of Life Support Systems : http://www.eolss.net/samplechapters/c10/e5-08-03-02.pdf

ECA Academy. (2015, Juli 10). Retrieved from European Compliance Academy: http://www.gmpcompliance.org/elements/pdf/8_production_ gmp2020.pdf

Homayounizadpanah, \& Baqerkord. (2012). Effect of Implementing Performance Management on theProductivity, Efficiency and Effectiveness of the Chabahar Municipal Employees. Research Journal of Applied Sciences, 4(12), 1767-1784.

Schermerhorn Jr., J. R. (2009). Management . New York: Wiley. 